\title{
Mechanism of cell death induced by the novel enzyme-prodrug combination, nitroreductase/CB 1954 , and identification of synergism with 5-fluorouracil
}

\author{
DH Palmer ${ }^{*, 1}$, AE Milner', DJ Kerr',2 and LS Young' \\ 'CR UK Institute for Cancer Studies, Clinical Research Block, University of Birmingham, Birmingham B 5 2TA, UK
}

\begin{abstract}
Virus-directed enzyme prodrug therapy (VDEPT) utilising the bacterial enzyme nitroreductase delivered by a replication-defective adenovirus vector to activate the prodrug CBI954 is a promising strategy currently undergoing clinical trials in patients with a range of cancers. An understanding of the mechanism of tumour cell death induced by activated CBI954 will facilitate this clinical development. Here, we report that activated CBI954 kills cells predominantly by caspase-dependent apoptosis. This may have important implications for the generation of immune-mediated bystander effects. Further, the use of a replication-defective adenovirus vector to deliver nitroreductase may negatively affect cellular apoptotic pathways stimulated by activated CBI954. Finally, examination of nitroreductase/CBI954 in combination with conventional chemotherapy reveals a synergistic interaction with 5fluorouracil. These data will facilitate the further development and future clinical trial design of this novel therapy.

British Journal of Cancer (2003) 89, 944-950. doi:I0.1038/sj.bjc.660121। www.bjcancer.com

(c) 2003 Cancer Research UK
\end{abstract}

Keywords: VDEPT; nitroreductase; CBI954; apoptosis; synergy; 5-fluorouracil

Epithelial ovarian cancer is the leading cause of death from gynaecological cancer with the majority of patients presenting with advanced intraperitoneal disease and requiring chemotherapy. The current standard treatment is a combination of carboplatin or cisplatin with paclitaxel. However, 5-year survival remains poor at $25-30 \%$. It is imperative therefore that novel treatments are developed.

Chemotherapeutic drugs can kill cells by activating apoptotic pathways and the exact mechanism by which this occurs is currently under intense investigation. Initial studies revealed that cytotoxic drugs can activate death receptor/caspase- 8 signalling pathways and this mechanism may be an essential factor in the early phase of drug-induced cell death depending on the cell type used (Friesen et al, 1996; Fulda et al, 1997, 1998a, b, 2000; Micheau et al, 1997). However, not all cell types require death receptorligand interaction for drugs to be effective (Gamen et al, 1997; Eischen et al, 1997; Villunger et al, 1997; Tolomeo et al, 1998; RuizRuiz and Lopez-Rivas, 1999). Recent studies have indicated that caspase- 8 can be activated independently of death receptor ligation (Milner et al, 2002). Interestingly, different drugs may engage distinct components of the apoptotic machinery (Milner et al, 2002). This is important since it may allow the use of different drugs to form potentially synergistic combinations.

A novel approach to cancer therapy currently entering clinical trials is Virus-Directed Enzyme Prodrug Therapy (VDEPT). This

*Correspondence: Dr DH Palmer; E-mail: danp@cancer.bham.ac.uk

${ }^{2}$ DJ Kerr's current address: Department of Clinical Pharmacology, Radcliffe Infirmary, University of Oxford, Woodstock Road, Oxford OX2 6HE, UK

Received 22 April 2003; revised 30 June 2003; accepted I July 2003 utilises an adenovirus delivered enzyme, nitroreductase (NR), to catalyse the conversion of a relatively nontoxic prodrug (CB1954) into an extremely potent DNA cross-linking agent. Preclinical studies have shown that adenoviral delivery of NR to a range of human cancer cell lines sensitises them to CB1954 by $500-2000$ fold compared to the parental cell line (Weedon et al, 2000). Further, in an in vivo xenograft model of peritoneal pancreatic cancer (Suit 2), a doubling in median survival was seen in mice treated with virus and CB1954 compared to controls $(P<0.0001)$ (Weedon et al, 2000).

In vitro cell mixing experiments using unmodified and NRexpressing ovarian carcinoma cell lines have demonstrated significant sensitisation $(30-100$-fold $)$ of the total cell population to CB1954 when only $5-10 \%$ of the cells express NR (McNeish et al, 1998). Similarly, in vivo in a human hepatoma murine xenograft model, a significant antitumour effect and improved survival were observed even when only $5 \%$ of cells expressed NR, confirming a significant bystander effect (Djeha et al, 2000). Interestingly, studies of other enzyme-prodrug combinations also suggest a 'distant bystander effect' thought to be a systemic immunemediated response to local tumour cell killing (Link et al, 1997). Other potential advantages of the NR/CB1954 combination are the ability to kill cells in a cell cycle-independent manner and the lack of cross-resistance with other commonly used cytotoxic agents (Bridgewater et al, 1995; Knox, 1998). A recent phase I clinical trial has confirmed that CB1954 is a well-tolerated prodrug that can be administered intravenously or intraperitoneally at doses sufficient for a VDEPT approach to be feasible in the treatment of ovarian cancer (Chung-Faye et al, 2001). A further clinical trial to assess the safety, tolerability and transgene expression of a replicationdeficient adenovirus vector carrying the gene for nitroreductase is ongoing. It is important, therefore, to investigate the mechanism 
by which activated CB1954 kills NR-expressing cancer cells. This will facilitate the further clinical development of this system in enhancing distant bystander effects and in devising rational combinations with conventional chemotherapeutic agents.

The aims of the current study are: (1) to determine the mode of cell death initiated by activated CB1954, (2) to identify the apoptotic pathways induced by activated CB1954 and in particular to identify any requirement for caspase activation, and (3) to assess the effect of CB1954 given in combination with a range of other chemotherapeutic agents in order to identify mechanistically synergistic drug combinations that may be utilised in future clinical trials.

\section{MATERIALS AND METHODS}

\section{Cells and cell culture}

The human ovarian carcinoma cell line SKOV3 was maintained in DME with HEPES, 10\% FCS and supplemented with glutamine. Stable NR-expressing SKOV3 cells (SKOV3NR) generated by infection with a retrovirus vector carrying the gene for $E$. coli bacterial nitroreductase were the kind gift of Dr PF Searle (University of Birmingham, UK).

\section{Detection of NR and caspases by Western blotting}

Cells were harvested, washed once in ice-cold PBS, pelleted by centrifugation and pellets lysed for $20 \mathrm{~min}$ on ice. Samples were pelleted at $13000 \mathrm{rpm}$ at $4^{\circ} \mathrm{C}$ and lysates decanted and stored at $-70^{\circ} \mathrm{C}$. Protein concentrations of total cell lysates were determined using a Biorad (Hercules, CA, USA) assay. Total cell lysate protein $(100 \mu \mathrm{g})$ was separated by SDS-PAGE and electroblotted onto nitrocellulose. Membranes were blocked with 5\% milk in PBSTween and then probed with either polyclonal nitroreductase antibody 108B (kindly provided by Dr M Ford, Glaxo-Wellcome, Stevenage, UK) diluted $1: 20000$, or polyclonal rabbit anti-caspase8 (a kind gift from Dr G Cohen, University of Leicester, UK; Sun et al, 1999) diluted 1:3000, monoclonal mouse anti-caspase-9 (Calbiochem) diluted 1:100, polyclonal rabbit anti-caspase-3 (Pharmingen, San Diego, CA, USA) diluted 1:5000. Immune complexes were detected with horseradish peroxidase-conjugated secondary antibodies (anti-rabbit diluted 1:2000; anti-mouse diluted 1:1000; Sigma, UK) and then visualised with ECL reagent (Amersham, UK) and autoradiography.

\section{Adenovirus infection of cells}

SKOV3 cells were plated out at a density of $2 \times 10^{6}$ cells ml $^{-1}$ in $75 \mathrm{~cm}^{3}$ flasks and allowed to attach overnight. The medium was removed and the cells were exposed to either RAd-NR, an E1-, E3deleted replication-defective adenovirus expressing bacterial NR from the CMV promoter, or a control $\beta$-galactosidase-expressing adenovirus (RAd35, kindly provided by Dr G Wilkinson, Cardiff, UK; Wilkinson and Akrigg, 1992), in $1 \mathrm{ml}$ of medium, rocking the flask every $20 \mathrm{~min}$. After $2 \mathrm{~h}$ the infection medium was removed and replaced with $12 \mathrm{ml}$ of fresh medium. After $48 \mathrm{~h}$, cells were harvested for Western blot analysis of NR expression, or treated with CB1954 prior to analysis of cell death.

\section{Flow cytometric analysis of cell viability}

Cells were plated out at a density of $2 \times 10^{5}$ cells ml $^{-1}$ in 48 -well plates and allowed to attach overnight. Following treatment with either CB1954 or chemotherapeutic drugs for $48 \mathrm{~h}$, cells were trypsinised and resuspended in $0.5 \mathrm{ml}$ saline (prewarmed to $37^{\circ} \mathrm{C}$ ). Syto 16 (Molecular Probes Europe, Leiden, Netherlands) was added at a concentration of $25 \mathrm{~nm}$ and incubated with the cells at room temperature for one $1 \mathrm{~h}$, at which time $5 \mu \mathrm{g} \mathrm{ml}^{-1}$ propidium iodide was added. Samples were analysed immediately on a Coulter EPICS XL flow cytometer. A two-dimensional dot plot was generated of Syto 16 fluorescence $v s$ propidium iodide fluorescence. Syto 16 is only taken up by viable cells and propidium iodide only enters cells whose membranes have become permeablised, therefore this technique distinguishes between viable cells (syto 16 + ve, propidium iodide -ve), apoptotic cells (syto 16 -ve, propidium iodide -ve) and necrotic cells (syto 16 -ve, propidium iodide + ve) (Schuurhuis et al, 1997). Data for $10^{4}$ cells were collected for each sample and prior to data collection cell debris was excluded by setting a gate on a forward $v s$ side scatter two-dimensional dot plot.

\section{Caspase inhibitors}

The cell-permeable caspase inhibitors IETD-FMK, LEHD-FMK, DEVD-FMK and ZVAD-FMK (Calbiochem, UK) were added to cells for $1 \mathrm{~h}$ prior to treatment with either CB1954 or chemotherapeutic drugs. Initially, a range of concentrations $(1-200 \mu \mathrm{M})$ was tested and from these experiments a concentration of $50 \mu \mathrm{M}$ was chosen for experiments in this study.

\section{MTT assay}

Cells were plated out at a density of $5 \times 10^{4}$ cells $\mathrm{ml}^{-1}$ in 96 -well plates and allowed to attach overnight prior to treatment. Following treatment, $20 \mu \mathrm{l}$ of $10 \mathrm{mg} \mathrm{ml}^{-1}$ MTT (3-(4,4-dimethylthiazol-2-yl)-2,5-diphenyl tetrazolium bromide) (Sigma) in PBS were added to each well and incubated for $4 \mathrm{~h}$ at $37^{\circ} \mathrm{C}$, and the formazan crystals formed were dissolved in DMSO. The absorbance was recorded at $550 \mathrm{~nm}$.

\section{Analysis of the cytotoxic effect of CB1954 in combination with other chemotherapeutic agents}

The effect of drug combinations was calculated according to the median effect principle described by Chou and Talalay (1984). Firstly, the dose-response curves for the cytotoxic effects of CB1954 and a panel of other drugs (cisplatin, 5-fluorouracil (5FU), topotecan, doxorubicin, paclitaxel, gemcitabine) in SKOV3 cells either stably expressing NR, or expressing NR delivered by an adenovirus vector, for each agent singly and in combination were constructed.

The median effect principle of mass action states that

$$
f_{\mathrm{a}} / f_{\mathrm{u}}=\left(D / D_{\mathrm{m}}\right)_{m}
$$

where $D$ is the drug dose, $D_{\mathrm{m}}$ the drug dose required for $50 \%$ cell kill, $f_{\mathrm{a}}$ the cell fraction affected, $f_{\mathrm{u}}$ the cell fraction unaffected, and $m$ the coefficient of sigmoidicity.

This equation can be linearised by taking logarithms of both sides so that $y=\log \left(f_{\mathrm{a}} / f_{\mathrm{u}}\right)$ is plotted with respect to $x=\log (D)$. From this, $m$ and $D_{\mathrm{m}}$ can be derived. Note that the linear correlation coefficient, $r$, describes the conformity of the data to the median effect principle. These data can then be used to determine the 'combination index' (CI), using the equation:

$$
\mathrm{CI}=(D) 1 /(D x) 1+(D) 2 /(D x) 2
$$

where $(D) 1$ and $(D) 2$ in combination kill $x \%$ of cells, and $(D x) 1$ and $(D x) 2$ are the doses of each drug alone that kill $x \%$ of cells.

If $\mathrm{CI}<1,=1$ or $>1$, then synergism, additive effect or antagonism is indicated, respectively. So, if the combined observed effect is greater than the calculated additive effect, synergism is indicated.

The validity of this methodology was demonstrated by confirmation of the previously reported synergistic interaction between cisplatin and 5-FU (data not shown) (Shirasaka et al, 1993; Tsai et al, 1993). 
946

\section{RESULTS}

\section{The mode of cell death induced by CB1954 is} predominantly apoptosis

The SKOV3 ovarian carcinoma cell line was either selected to stably express NR after retroviral transduction or infected with RAd-NR to produce transient NR expression. A comparison of the levels of NR expression showed that RAd-NR was able to deliver NR in a dose-dependent manner successfully with a virus dose of moi 10 resulting in similar levels of NR expression to that seen in the stably expressing cell line (Figure 1A). Further, NR sensitised SKOV3 cells to the prodrug CB1954 as measured by MTT assay, the amount of cell death correlating with the level of NR expression (Figure 1B).

Parental SKOV3 cells and SKOV3NR cells were treated with CB1954 over a range of concentrations. After $48 \mathrm{~h}$, FACS analysis was performed to determine the degree of cell death induced and the relative amounts of apoptosis and necrosis. Figure 2B demonstrates that the mode of cell death induced by activated CB1954 in this setting was predominantly apoptosis, in common with a range of other chemotherapeutic agents (data not shown and Milner et al, 2002). In addition, RAd-NR infected SKOV3 cells were treated with CB1954 and similar analysis was performed. This confirmed that apoptosis was the predominant form of cell death induced and that the degree of apoptosis increased in proportion with increasing NR expression and increasing CB1954 dose (Figure $2 \mathrm{C}$ and $\mathrm{D}$ ). In the absence of NR, CB1954 was toxic only at very high concentration (Figure 2A).

A

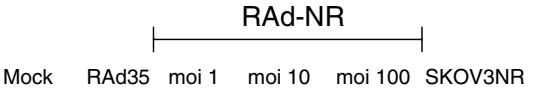

B

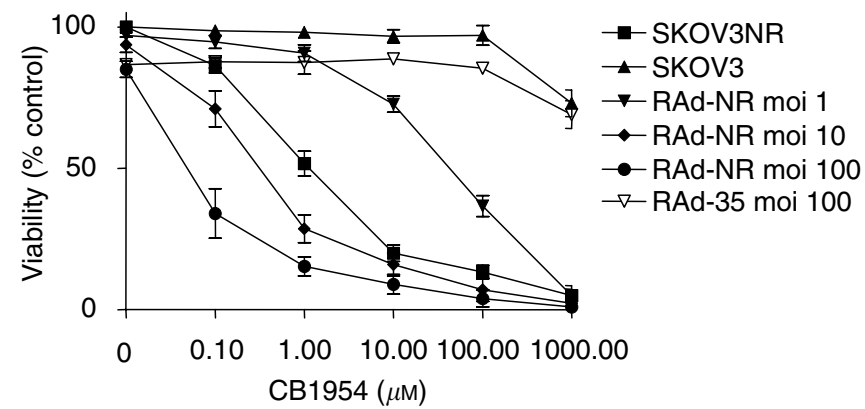

Figure I A replication-deficient adenovirus vector carrying the gene encoding bacterial NR results in NR expression and sensitisation to CBI954 cytotoxicity in SKOV3 cells. (A) SKOV3 cells were infected with RAd-NR and the presence of NR protein was assessed $48 \mathrm{~h}$ later by Western blot analysis. Lane I, mock infection; lane 2, control virus (RAd35) moi 100; lane 3, RAd-NR moi I; lane 4, RAd-NR moi 10; lane 5, RAdNR moi 100; lane 6, stable NR-expressing SKOV3. (B) SKOV3 cells were mock infected, infected with control virus or with RAd-NR (moi I, I0, 100). After $48 \mathrm{~h}$, cells were treated with CB 1954 over a range of doses (0, $0.1,1,10,100$ or $1000 \mu \mathrm{M})$. SKOV3 cells stably expressing NR were similarly treated. After a further $48 \mathrm{~h}$, cell viability was assessed by MTT assay. Results are expressed as a percentage of the absorbance of untreated cells and are the mean of three separate experiments \pm s.e.

\section{Activated CB1954 initiates activation of caspase-8, -9 and -3}

Stably expressing SKOV3NR cells were treated with a panel of drugs commonly used in the treatment of ovarian cancer and with CB1954 at doses sufficient to induce apoptosis in approximately $70 \%$ of the cells. Western blot analysis for caspase- $8,-9$, and -3 revealed that the active form of each caspase could be clearly detected following treatment with all drugs including activated CB1954 (Figure 3A). However, in the absence of NR, CB1954 was unable to initiate apoptosis or activate any of these caspases (Figure 3A).

SKOV3 cells transiently expressing NR were also treated with CB1954 to induce high levels of apoptosis and similar Western blots were performed. Again, activation of caspase-8, -9, and -3 was seen. RAd-NR infection alone or CB1954 treatment of cells infected with a control adenovirus vector did not result in apoptosis or caspase activation (Figure 3B).

\section{The relative contribution of caspases to the induction of apoptosis differs between RAd-NR infected and stable NR-expressing cells treated with CB1954, and between CB1954 and other chemotherapeutic agents}

To determine whether the caspase activation seen in Figure 3 is essential for the mechanism of CB1954 induced cell death, stably expressing SKOV3NR cells were treated with CB1954 or one of a range of other drugs either in the presence or absence of specific inhibitors of caspase-3, -8 , or -9 , or a broadspectrum caspase inhibitor, ZVAD-FMK. We have previously shown that at a concentration of $50 \mu \mathrm{M}$, DEVD-FMK (caspase-3 inhibitor), IETD-FMK (caspase-8 inhibitor) and LEHD-FMK (caspase-9 inhibitor) work in a specific manner (Milner et al, 2002). Therefore, this concentration was used for all the inhibitors in these experiments. Figure 4 shows the levels of cell death induced at $48 \mathrm{~h}$ by either drugs alone or when cells were preincubated with the inhibitors for $1 \mathrm{~h}$ prior to drug treatment.

Pretreatment with the broad-spectrum ZVAD inhibited apoptosis induced by activated CB1954 or by the other drugs used, confirming that apoptosis was caspase-dependent. In addition, pretreatment with each of the specific caspase inhibitors alone resulted in a significant reduction in the level of apoptosis induced by all the conventional cytotoxic drugs (Figure 4C, D and data not shown). However, pretreatment of stably expressing SKOV3NR cells with individual inhibitors alone was not sufficient to decrease CB1954-induced apoptosis, although this was significantly reduced by a combination of caspase- 8 and -9 inhibitors. Apoptosis induced by CB1954 after RAd-NR infection was again inhibited by ZVAD. However, in this setting, the specific caspase- 9 inhibitor (but not the caspase- 8 inhibitor) also resulted in a partial reduction in the level of apoptosis, although a more profound inhibition resulted from combined pretreatment with caspase- 8 and -9 inhibitors.

\section{Combination treatment with CB1954 plus 5-FU causes enhanced tumour cell kill}

As the above experiments indicated that apoptotic pathways and, specifically, the relative contribution of caspases activated by CB1954 differ from those initiated by other cytotoxic agents, it was of interest to determine whether combining CB1954 with any of these agents could cause an increase in cell death.

Stably expressing SKOV3NR cells were treated with CB1954 simultaneously with one of 5-FU, cisplatin, topotecan, doxorubicin, paclitaxel or gemcitabine over a range of drug concentrations. After $48 \mathrm{~h}$, cell viability was assessed using the MTT assay. These 
A

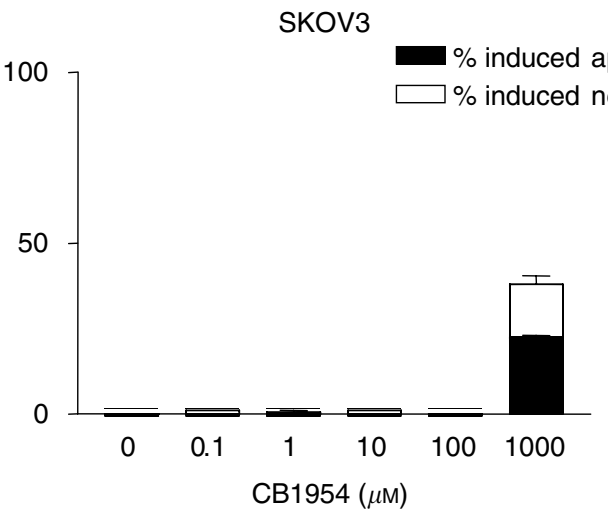

B

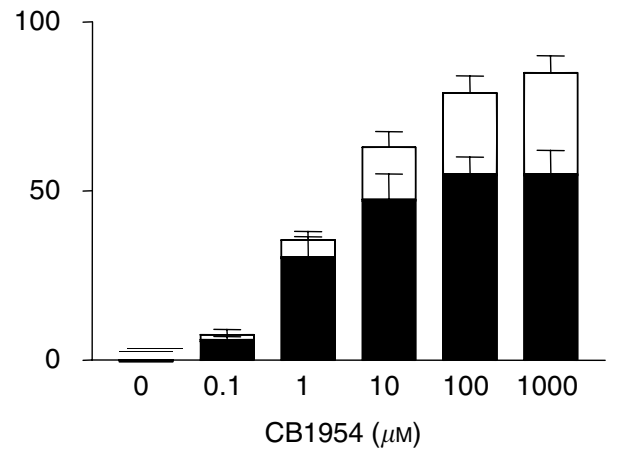

C

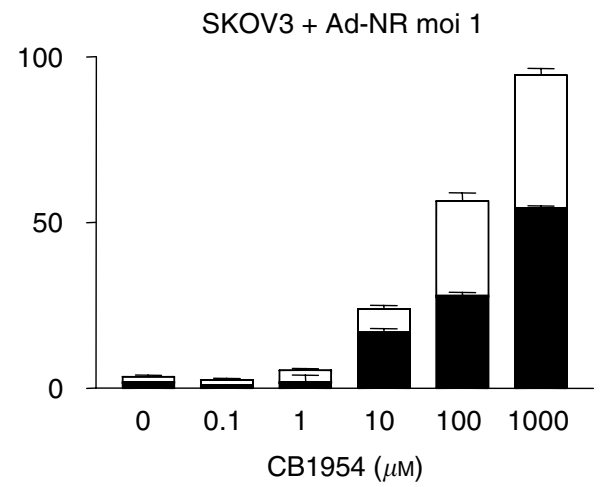

D SKOV3 + Ad-NR moi 10

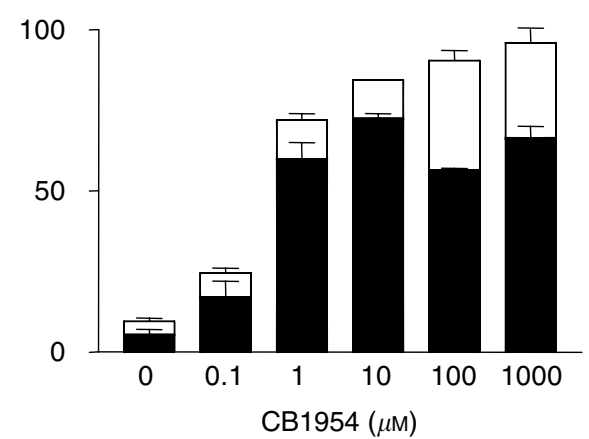

Figure 2 Analysis of the mode of cell death induced by activated CBI954. SKOV3 cells were infected with RAd-NR and then treated with CBI954 as described in Figure I. The proportion of apoptotic and necrotic cell death was determined by FACS analysis. Results are the mean of three separate experiments \pm s.e. (A) Parental SKOV3, no NR expression; (B) SKOV3 cells stably expressing NR; (C) RAd-NR moi I; (D) RAd-NR moi 10.

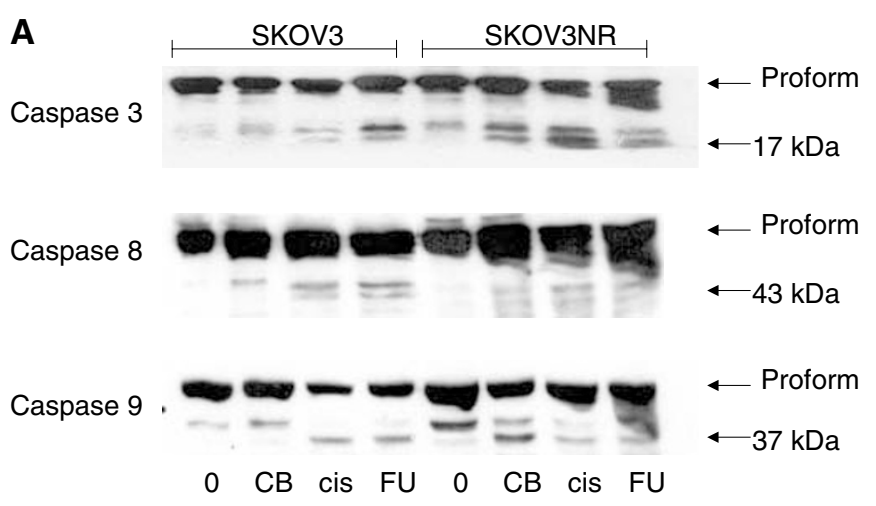

B

Caspase 3

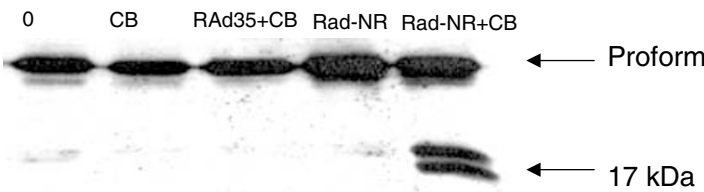

Caspase 8

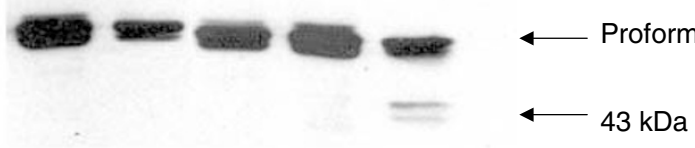

Caspase 9
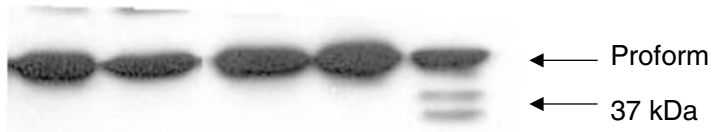

$\longleftarrow 37 \mathrm{kDa}$

Figure 3 Caspase cleavage by activated CBI954. (A) SKOV3 and stable NR expressing SKOV3 cells were treated with CB1954, cisplatin or 5fluorouracil at doses sufficient to cause apoptosis in approximately $70 \%$ of cells (confirmed on samples prepared in parallel and analysed by FACS, data not shown). The dose of CBI954 used to treat parental SKOV3 cells was that which induced $70 \%$ apoptosis in NR-expressing cells. At this dose, no apoptosis was observed in the parental cells. After $48 \mathrm{~h}$, the activation of caspase- $3,-8$ and -9 was assessed by Western blot analysis. Antibodies able to recognise both proform and active form of each caspase were used. Lanes I-4, parental SKOV3 cells; lanes 5-8, stable NR expressing cells. Lanes I and 5, no drug; lanes 2 and 6, CB।954 10 $\mu \mathrm{M}$; lanes 3 and 7, cisplatin I0 $\mu \mathrm{M}$; lanes 4 and 8, 5-FU $500 \mu \mathrm{M}$. (B) SKOV3 cells were infected with RAd-NR (moi I0) or control adenovirus, RAd-35 (moi I0). After $48 \mathrm{~h}$, cells were treated with CBI954 10 $\mathrm{M}$. After a further $48 \mathrm{~h}$, caspase cleavage was assessed as in (A). Lane I, untreated control; lane 2, CB 1954 alone; lane 3, RAd-35 + CBI954; lane 4, RAd-NR alone; lane 5, RAd$N R+C B \mid 954$.

data were then used to calculate 'CI' plots to assess whether drug combinations were synergistic, additive or antagonistic. It was demonstrated that CB1954 in combination with 5-FU produced a synergistic enhancement of cell killing over a wide range of drug concentrations in both SKOV3NR cells and SKOV3 cells infected with RAd-NR. Of note, in the absence of NR, CB1954 did not potentiate 5-FU cytotoxicity. The addition of cisplatin, topotecan, doxorubicin, paclitaxel or gemcitabine to CB1954 resulted in, at best, additive cell killing and in some cases was even antagonistic (Figure 5 and data not shown). Similar results, specifically demonstrating synergy between activated CB1954 and 5-FU, have been obtained in human colon cancer cell lines (WiDr and SW480, data not shown). 
A

SKOV3NR+CB1954

B SKOV3+RAd-NR+CB1954
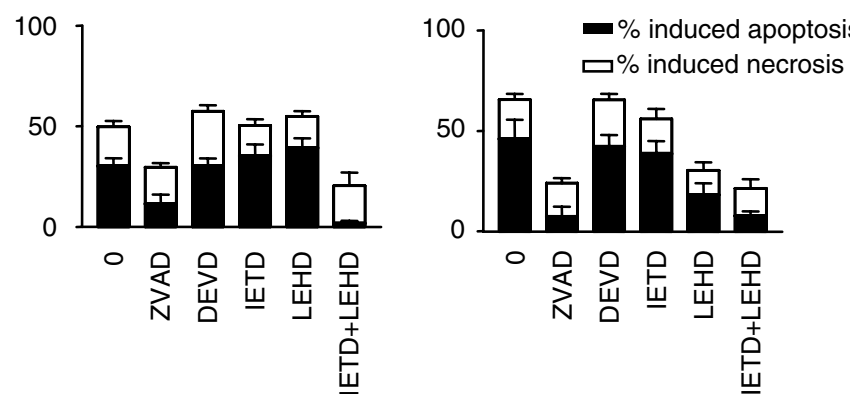

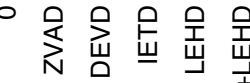

C
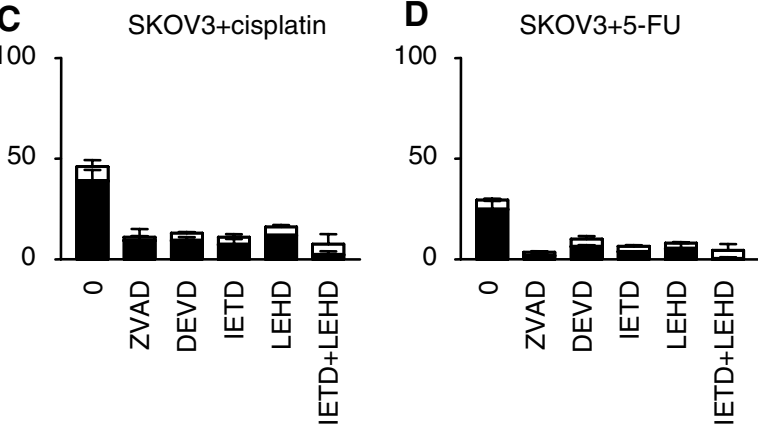

A

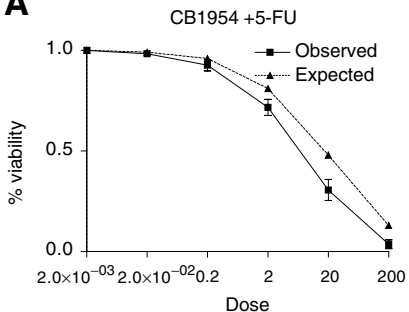

B

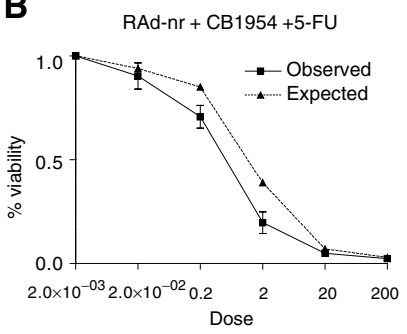

C

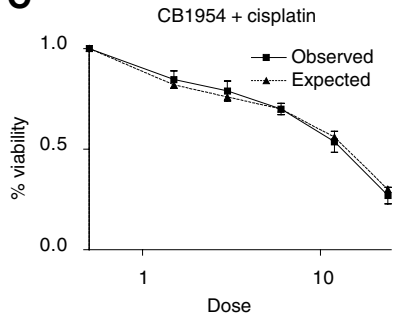

D

Figure 4 Effect of caspase inhibitors on CBI954-induced cell death SKOV3 cells stably expressing NR $(\mathbf{A})$, or infected with RAd-NR moi IO (B), were treated with CBI954 10 $\mathrm{M}$ in the presence or absence of a broad-spectrum caspase inhibitor (ZVAD-FMK, $50 \mu \mathrm{M}$ ), a caspase-3 like inhibitor (DEVD-FMK, $50 \mu \mathrm{M}$ ), a caspase-8-like inhibitor (IETD-FMK, $50 \mu \mathrm{M}$ ) or a caspase-9 like inhibitor (LEHD-FMK, $50 \mu \mathrm{M})$. SKOV3 cells were treated with cisplatin $(10 \mu \mathrm{M})$ or $5-\mathrm{FU}(500 \mu \mathrm{M})$ also in the presence or absence of caspase inhibitors $(\mathbf{C})$ and $(\mathbf{D})$. The levels of cell death were analysed $48 \mathrm{~h}$ later by FACS. Results are the mean of three independent experiments \pm s.e.

\section{DISCUSSION}

In this study, we have investigated the mechanism of cell death induced by the VDEPT combination of NR and CB1954 in ovarian carcinoma cells and have demonstrated a synergistic interaction between activated CB1954 and 5-FU.

In common with a range of cytotoxic drugs with diverse mechanisms of action, cell death induced by activated CB1954 was predominantly apoptotic rather than necrotic. This distinction is important as it is thought that apoptotic cell death may not be optimal in generating immune responses to tumour antigens, which might enhance tumour cell killing in vivo (Melcher et al, 1999; Steinman et al, 2000). So, immune-mediated bystander killing in vivo may be enhanced by combined NR/CB1954 gene therapy with immunostimulatory molecules such as GM-CSF (Green et al, 2003).

Apoptosis induced by activated CB1954 was dependent upon caspase activation as indicated by the effect of the broad-spectrum caspase inhibitor, ZVAD. However, the relative contribution of caspases to CB1954-induced apoptosis differed from other cytotoxic drugs. Thus, inhibition of either caspase-3, -8 or -9 alone was effective in reducing levels of apoptosis induced by all the conventional cytotoxic drugs tested suggesting that these are critical effectors of apoptosis. However, when CB1954 was activated in cells stably expressing $\mathrm{NR}$, although caspase- $3,-8$ and -9 were cleaved, inhibition
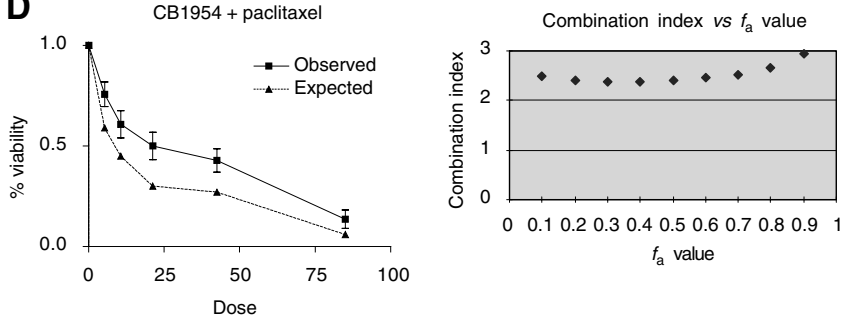

Figure 5 Analysis of cytotoxicity induced by CBI954 in combination with other chemotherapeutic agents. Cell viability in response to treatment with drug combinations was assessed by MTT assay and results expressed as a percentage of the absorbance of untreated cells (solid line; mean of three experiments \pm s.e.). The expected effect of each drug combination based on an additive interaction was calculated (broken line). Therefore, synergistic interactions will be to the left and antagonistic interactions to the right of calculated curve. (A) Stable NR expressing SKOV3 cells were treated with CBI954 over a range of doses $(0-1000 \mu \mathrm{M})$, in combination with 5 -FU in a fixed dose ratio $(1: 100)$ according to the median effect principle of mass action. After $48 \mathrm{~h}$, cell viability was assessed by MTT. (C) CBI954 in combination with cisplatin (dose ratio I: I). (D) CBI954 in combination with paclitaxel (dose ratio 10:I). (B) SKOV3 cells were infected with RAd-NR (moi I) and $48 \mathrm{~h}$ later treated as in $(\mathbf{A})$. All results are the mean of three independent experiments \pm s.e. The combination index is also shown for each drug combination, where a value of $I=$ additive, $<\mid=$ synergistic and $>\mid=$ antagonistic.

of either one alone was not sufficient to block apoptosis. Inhibition of caspase- 8 and -9 together did significantly reduce apoptosis. This indicates that activated CB1954 may activate caspase- 8 and -9 separately, either one of which is sufficient for apoptosis, rather than caspase- 9 cleavage occurring downstream of caspase- 8 via bid cleavage, as reported for other apoptotic stimuli. This is consistent with previous reports indicating that deficiency of certain caspases can result in compensatory activation of alternative caspase pathways, suggesting a degree of redundancy in death activating pathways (Zheng et al, 2000). 
Interestingly, a different pattern was observed when NR was delivered via an adenovirus vector, with caspase-9 inhibition resulting in a partial reduction in apoptosis. This may be explained by the effect of the adenovirus vector upon antiapoptotic cellular pathways. Indeed, we have demonstrated that such vectors activate the NF- $\kappa \mathrm{B}$ pathway which in turn upregulates expression of antiapoptotic cellular pathways (manuscript submitted). Other studies have reported that NF- $\kappa \mathrm{B}$ inducible factors can act by inhibiting caspase- 8 activity downstream of its cleavage to the active form (Wang et al, 1998; You et al, 2001). Therefore, the adenovirus vector may activate cellular pathways resulting in caspase- 8 inhibition, so that the additional inhibition of caspase- 9 may reduce CB1954-induced apoptosis. These effects may be important, since adenovirus delivery of prodrug-activating enzymes or other cytotoxic agents is a major focus of cancer gene therapy protocols. These data will prove useful in the further development of this novel therapy and will facilitate the rational study of NR/CB1954 in combination with other novel anticancer strategies or with conventional chemotherapy.

The current study has addressed the effect of CB1954 given in combination with other drugs to investigate whether potentially synergistic combinations could be identified.

Using the median effect principle of mass action, it was possible to calculate the expected effect of a combination of drugs based on knowledge of their individual effects. This was then compared to the observed effect achieved by the drug combination. The ratio of the expected to the observed effect is the
' $\mathrm{CI}$ ' so that $\mathrm{CI}<1$ indicates a synergistic interaction, $\mathrm{CI}=1$ indicates an additive effect and $\mathrm{CI}>1$ indicates antagonism. CB1954 treatment of SKOV3 cells stably expressing NR in combination with cisplatin, topotecan, doxorubicin, paclitaxel or gemcitabine demonstrated at best additive and in some cases even antagonistic interaction. Conversely, the combination of CB1954 with 5-FU was found to be synergistic across a wide range of doses. This effect was observed whether NR was expressed stably or delivered via an adenovirus vector. These data suggest that, if VDEPT is to be used in combination with conventional chemotherapy, the clinical outcome may be critically dependent upon the drugs chosen. As early phase clinical trials of other VDEPT systems or conditionally replicating adenoviruses in combination with conventional chemotherapy have reported this to be a safe, feasible approach with promising evidence of efficacy, the data presented here will prove useful in the rational design of future clinical trials of VDEPT using NR/CB1954 (Khuri et al, 2000).

It will also be important to carry out further research to determine why NR/CB1954 can synergise with some drugs, but have an inhibitory effect with others. Since there are differences in the pathways upstream of caspase cleavage activated by drugs with different intracellular targets, this may determine the interaction of drug combinations. Alternatively, synergy may be related to effects on cell cycle progression (given that 5-FU is a cell cycle-specific drug), effects on mechanisms of drug resistance, interference with activation/inactivation of active metabolites, effects on DNA repair mechanisms or other undefined mechanisms.

\section{REFERENCES}

Bridgewater JA, Springer CJ, Knox RJ, Minton NP, Michael NP, Collins MK (1995) Expression of the bacterial nitroreductase enzyme in mammalian cells renders them selectively sensitive to killing by the prodrug CB1954. Eur J Cancer 31A(13-14): 2362-2370

Chou TC, Talalay P (1984) Quantitative analysis of dose-effect relationships: the combined effects of multiple drugs or enzyme inhibitors. Adv Enzyme Regul 22: 27-55

Chung-Faye G, Palmer D, Anderson D, Clark J, Downes M, Baddeley J, Hussain S, Murray PI, Searle P, Seymour L, Harris PA, Ferry D, Kerr DJ (2001) Virus-directed, enzyme prodrug therapy with nitroimidazole reductase: a phase I and pharmacokinetic study of its prodrug, CB1954. Clin Cancer Res 7(9): 2662-2668

Djeha AH, Hulme A, Dexter MT, Mountain A, Young LS, Searle PF, Kerr DJ, Wrighton CJ (2000) Expression of Escherichia coli B nitroreductase in established human tumor xenografts in mice results in potent antitumoral and bystander effects upon systemic administration of the prodrug CB1954. Cancer Gene Ther 7(5): $721-731$

Eischen CM, Kottke TJ, Martins LM, Basi GS, Tung JS, Earnshaw WC, Leibson PJ, Kaufmann SH (1997) Comparison of apoptosis in wild-type and Fas-resistant cells: chemotherapy-induced apoptosis is not dependent on Fas/Fas ligand interactions. Blood 90(3): 935-943

Friesen C, Herr I, Krammer PH, Debatin KM (1996) Involvement of the CD95 (APO-1/FAS) receptor/ligand system in drug-induced apoptosis in leukemia cells. Nat Med 2(5): 574-577

Fulda S, Los M, Friesen C, Debatin KM (1998a) Chemosensitivity of solid tumor cells in vitro is related to activation of the CD95 system. Int $J$ Cancer 76(1): 105-114

Fulda S, Scaffidi C, Pietsch T, Krammer PH, Peter ME, Debatin KM (1998b) Activation of the CD95 (APO-1/Fas) pathway in drug- and gammairradiation-induced apoptosis of brain tumor cells. Cell Death Differ 5(10): $884-893$

Fulda S, Sieverts H, Friesen C, Herr I, Debatin KM (1997) The CD95 (APO$1 /$ Fas) system mediates drug-induced apoptosis in neuroblastoma cells. Cancer Res 57(17): 3823-3829

Fulda S, Strauss G, Meyer E, Debatin KM (2000) Functional CD95 ligand and CD95 death-inducing signaling complex in activation-induced cell death and doxorubicin-induced apoptosis in leukemic T cells. Blood 95(1): $301-308$
Gamen S, Anel A, Lasierra P, Alava MA, Martinez-Lorenzo MJ, Pineiro A, Naval J (1997) Doxorubicin-induced apoptosis in human T-cell leukemia is mediated by caspase-3 activation in a Fas-independent way. FEBS Lett 417(3): $360-364$

Green NK, McNeish IA, Doshi R, Searle PF, Kerr DJ, Young LS (2003) Immune enhancement of nitroreductase-induced cytotoxicity: studies using a bicistronic adenovirus vector. Int J Cancer 104(1): $104-112$

Khuri FR, Nemunaitis J, Ganly I, Arseneau J, Tannock IF, Romel L, Gore M, Ironside J, MacDougall RH, Heise C, Randlev B, Gillenwater AM, Bruso P, Kaye SB, Hong WK, Kirn DH (2000) A controlled trial of intratumoral ONYX-015, a selectively replicating adenovirus, in combination with cisplatin and 5-fluorouracil in patients with recurrent head and neck cancer. Nat Med 6(8): 879-885

Knox RJ (ed). (1998) Targeted Anti-cancer Therapies: are They ADEPT or INEPT? Greenwich, United Kingdom: The University of Greenwich Inaugural Lecture Series

Link Jr CJ, Levy JP, McCann LZ, Moorman DW (1997) Gene therapy for colon cancer with the herpes simplex thymidine kinase gene. J Surg Oncol 64(4): 289-294

McNeish IA, Green NK, Gilligan MG, Ford MJ, Mautner V, Young LS, Kerr DJ, Searle PF (1998) Virus directed enzyme prodrug therapy for ovarian and pancreatic cancer using retrovirally delivered E. coli nitroreductase and CB1954. Gene Therapy 5(8): $1061-1069$

Melcher A, Gough M, Todryk S, Vile R (1999) Apoptosis or necrosis for tumor immunotherapy: what's in a name? J Mol Med 77(12): $824-833$

Micheau O, Solary E, Hammann A, Martin F, Dimanche-Boitrel MT (1997) Sensitization of cancer cells treated with cytotoxic drugs to fas-mediated cytotoxicity. J Natl Cancer Inst 89(11): 783-789

Milner AE, Palmer DH, Hodgkin EA, Eliopoulos AG, Knox PG, Poole CJ, Kerr DJ, Young LS (2002) Induction of apoptosis by chemotherapeutic drugs: the role of FADD in activation of caspase- 8 and synergy with death receptor ligands in ovarian carcinoma cells. Cell Death Differ 9(3): $287-300$

Ruiz-Ruiz MC, Lopez-Rivas A (1999) p53-mediated up-regulation of CD95 is not involved in genotoxic drug-induced apoptosis of human breast tumor cells. Cell Death Differ 6(3): 271-280 
Schuurhuis GJ, Oberink JW, Bontje PM, Broxterman HJ (1997) The PGP specific combination Syto ${ }^{\circledR}$ 16/PSC833 detects early apoptosisin CD34 positive progenitor cells. Exp Hematol 25: 754

Shirasaka T, Shimamoto Y, Ohshimo H, Saito H, Fukushima M (1993) Metabolic basis of the synergistic antitumor activities of 5-fluorouracil and cisplatin in rodent tumor models in vivo. Cancer Chemother Pharmacol 32(3): $167-172$

Steinman RM, Turley S, Mellman I, Inaba K (2000) The induction of tolerance by dendritic cells that have captured apoptotic cells. J Exp Med 191(3): $411-416$

Sun XM, MacFarlane M, Zhuang J, Wolf BB, Green DR, Cohen GM (1999) Distinct caspase cascades are initiated in receptor-mediated and chemical-induced apoptosis. J Biol Chem 274(8): 5053-5060

Tolomeo M, Dusonchet L, Meli M, Grimaudo S, D’Alessandro N, Papoff G, Ruberti G, Rausa L (1998) The CD95/CD95 ligand system is not the major effector in anticancer drug-mediated apoptosis. Cell Death Differ 5(9): $735-742$

Tsai CM, Hsiao SH, Frey CM, Chang KT, Perng RP, Gazdar AF, Kramer BS (1993) Combination cytotoxic effects of cis-diamminedichloroplatinu$\mathrm{m}(\mathrm{II})$ and 5-fluorouracil with and without leucovorin against human non-small cell lung cancer cell lines. Cancer Res 53(5): 1079-1084

Villunger A, Egle A, Kos M, Hartmann BL, Geley S, Kofler R, Greil R (1997) Drug-induced apoptosis is associated with enhanced Fas (Apo-1/CD95) ligand expression but occurs independently of Fas (Apo-1/CD95) signaling in human T-acute lymphatic leukemia cells. Cancer Res 57(16): $3331-3334$

Wang CY, Mayo MW, Korneluk RG, Goeddel DV, Baldwin Jr AS (1998) NF-kappaB antiapoptosis: induction of TRAF1 and TRAF2 and c-IAP1 and c-IAP2 to suppress caspase-8 activation. Science 281(5383): $1680-1683$

Weedon SJ, Green NK, McNeish IA, Gilligan MG, Mautner V, Wrighton CJ, Mountain A, Young LS, Kerr DJ, Searle PF (2000) Sensitisation of human carcinoma cells to the prodrug CB1954 by adenovirus vector-mediated expression of $E$. coli nitroreductase. Int $J$ Cancer 86(6): $848-854$

Wilkinson GW, Akrigg A (1992) Constitutive and enhanced expression from the CMV major IE promoter in a defective adenovirus vector. Nucleic Acids Res 20(9): 2233-2239

You Z, Ouyang H, Lopatin D, Polver PJ, Wang CY (2001) Nuclear factorkappa B-inducible death effector domain-containing protein suppresses tumor necrosis factor-mediated apoptosis by inhibiting caspase- 8 activity. J Biol Chem 276(28): 26398-26404

Zheng TS, Hunot S, Kuida K, Momoi T, Srinivasan A, Nicholson DW, Lazebnik Y, Flavell RA (2000) Deficiency in caspase-9 or caspase-3 induces compensatory caspase activation. Nat Med 6(11): $1241-1247$ 